\title{
Museus de ciências em tempos de pandemia: uma análise no Instagram do museu da vida
}

\section{Science museums in times of pandemic: an analysis in the Instagram of the Museum of Life}

\author{
${ }^{1}$ Thatyana Pimentel Rodrigo de Freitas thatyana.freitas.2020@gmail.com \\ ${ }^{2}$ Júlia Beatriz Andrade Silveira \\ ${ }^{3}$ Pedro Miguel Marques da Costa \\ ${ }^{4}$ Bruna Sarpa Miceli \\ ${ }^{5}$ Marcelo Borges Rocha
}

\section{RESUMO}

Neste estudo foi realizada uma análise netnográfica no Instagram do Museu da Vida (MV) da FIOCRUZ, com o objetivo de investigar como o museu continuou realizando atividades educativas e de divulgação científica, apesar do fechamento devido à pandemia da Covid-19. Os dados coletados foram publicados na rede social, nos dois primeiros meses do período de isolamento social decretado pelo governo do estado do Rio de Janeiro. Houve um total de 96 postagens que se utilizaram de recursos textuais, imagéticos e audiovisuais, para divulgar vídeos com experimentos, informações sobre cientistas brasileiras negras, entre outros. O MV realizou sua primeira live durante a pandemia e convidou um biólogo para interagir com a sociedade sobre aspectos relacionados ao coronavírus e prestar esclarecimentos sobre fake news no contexto da pandemia. Portanto, apesar do fechamento, o museu deu prosseguimento às atividades educativas e de divulgação científica pelo Instagram, ampliando a visibilidade do museu para além de seu espaço físico. Palavras-chave: Instagram; divulgação científica; museus de ciências; Covid-19; coronavírus

\section{ABSTRACT}

In this study, a netnographic analysis was carried out on the Instagram of the Museum of Life (MV) of FIOCRUZ, in order to investigate how the museum continued to carry out educational and outreach activities despite the closure due to the Covid-19 pandemic. The collected data were published in the social network, in the first two months of the period of social isolation decreed by the state government from Rio de Janeiro. There were a total of 96 posts that used textual, imagery and audiovisuals, to disseminate videos with experiments, information about black Brazilian scientists, among others. The MV held his first live during the pandemic and invited a biologist to interact with the society on aspects related to the coronavirus and provide clarification on fake news in the context of the pandemic. Therefore, despite the closure, the museum continued its educational activities and scientific dissemination on Instagram, expanding the museum's visibility beyond its physical space.

Keywords: Instagram. Scientific divulgation. Science museums. Covid-19. Coronavirus.

1 Mestranda do Programa de Mestrado Profissional em Educação, Gestão e Difusão em Biociências do Instituto de Bioquímica Médica da Universidade Federal do Rio de Janeiro (IBqM/UFRJ)

2 Mestranda do Programa de Pós-Graduação em Ciência, Tecnologia e Educação do Centro Federal de Educação Tecnológica Celso Suckow da Fonseca (CEFET/RJ)

3 Doutorando do Programa de Pós-Graduação em Ciência, Tecnologia e Educação do Centro Federal de Educação Tecnológica Celso Suckow da Fonseca (CEFET/RJ)

4 Doutoranda do Programa de Pós-Graduação em Ciência, Tecnologia e Educação do Centro Federal de Educação Tecnológica Celso Suckow da Fonseca (CEFET/RJ)

5 Doutor em Ciências Biológicas pela Universidade Federal do Rio de Janeiro (UFRJ). Docente do Programa de Pós-Graduação em Ciência, Tecnologia e Educação no Centro Federal de Educação Tecnológica Celso Suckow da Fonseca (CEFET/RJ), do Programa de Mestrado Profissional em Educação, Gestão e Difusão em Biociências no Instituto de Bioquímica Médica da Universidade Federal do Rio de Janeiro (IBqM/UFRJ) e do Instituto NUTES. 


\section{INTRODUÇÃO}

Segundo Pscheidt e Lorenzetti (2020), os museus de ciências são instituições que realizam ações variadas para diferentes públicos, proporcionando experiências culturais, científicas e cotidianas. Desta forma, o público tem acesso ao conhecimento científico de forma contextualizada e prática. Assim, Massarani et al. (2019) inferem que os museus de ciências representam espaços de interface entre ciência, cultura e sociedade, visto que apresentam objetivos variados de educação, informação, lazer e cultura.

Entretanto, Massarani et al. (2019) observaram que a maioria dos jovens, embora tenha interesse sobre temas científicos, não costuma frequentar museus, centros de ciências e jardins botânicos. Esses dados indicam a necessidade de se repensar como têm sido as ações de aproximação entre esses espaços e a sociedade. Entendendo a demanda que se configura com essa nova geração de público, torna-se necessário que os museus estejam preparados para novos empreendimentos e parcerias (DRUMM, 2020).

Nesse sentido, o desenvolvimento das tecnologias de informação e comunicação teve um impacto relevante no museu e na sua relação com os públicos virtuais, propondo uma redefinição do conceito de museu e do objeto museal (BOYS; BODDINGTON, 2014). Essa situação torna-se ainda mais latente nos tempos em que o mundo está sendo abalado pela pandemia da Covid-19, momento em que é necessário repensar as relações profissionais, educacionais, pessoais e sociais, uma vez que o distanciamento e o isolamento social se fazem necessários. Com isso, a pandemia fez com que os museus de ciências reavaliassem e ampliassem suas formas de comunicação com o público.

Exposto esse cenário, torna-se relevante pensar acerca das estratégias educativas e de divulgação científica (DC) dos museus de ciências em tempos da Covid-19. Sabe-se que foi necessário que estes espaços cancelassem as visitações presenciais, mas essa situação não impediu que ações continuassem ocorrendo. Depois que tudo isso passar, espera-se que essas recentes habilidades e experiências sejam transferidas para a sustentabilidade dos museus em longo prazo (COUNTS, 2020).

Em tempos de pandemia, os museus, como nunca visto antes, possuem uma oportunidade de repensar sua missão, visão e impacto, buscando descobrir como podem responder às necessidades da sociedade e serem mais relevantes para diversos públicos, bem como mais ágeis em responder a um mundo em rápida mudança (DECATUR, 2020).

Diante do exposto, o presente estudo focou nas ações educativas e de DC do Museu da Vida, inaugurado em 25 de maio de 1999, como parte da Casa de Oswaldo Cruz (COC). O Museu localiza-se no campus de Manguinhos da Fundação Oswaldo Cruz (FIOCRUZ), no Rio de Janeiro, ocupando diferentes espaços do campus. A COC dedica-se à história, ao patrimônio cultural e à divulgação das ciências e da saúde. Assim, o Museu da Vida, tem como um de seus objetivos a preservação da memória da FIOCRUZ por meio de práticas de DC, pesquisa, ensino e documentação da história da saúde pública no Brasil.

Através dos dados coletados nesta pesquisa podemos refletir sobre os impactos da Covid-19 na ciência e nas práticas educativas dos museus. Pesquisas durante o período de pandemia fornecerão dados para se repensar a prática de DC a partir de outros mecanismos que não só as visitas presenciais, como, por exemplo, o papel assumido pelas redes sociais.

O uso dessas redes pode favorecer a ampliação do contato dos indivíduos com a ciência, demonstrando o valor e a relevância do processo de construção do conhecimento científico. Isso se justifica em momentos em que se discute a importância de produzir uma vacina eficaz contra a Covid-19, em que se investigam medicamentos para o tratamento da doença, em que se problematiza a importância do isolamento social, entre tantas outras questões. Fica claro, assim, que neste momento de pandemia, torna-se ainda mais emergencial promover a reestruturação e a revalorização da ciência. 
De acordo com Campos e Costa (2019), há diversos tipos de redes sociais: profissionais (Linkedin), textos curtos (Twitter), vídeos (Youtube), fotos (Instagram), amizades (Facebook), entre outras. Uma das redes sociais que mais cresceu no mundo em número de usuários é o Instagram (SHELDON; BRYANT, 2016). Com origem em 2010, o Instagram é considerado uma rede social relativamente nova que permite o compartilhamento de fotos e vídeos (HU; MANIKONDA; KAMBHAMPATI, 2014). Para Suess (2014), a popularidade da plataforma é um reflexo da crescente cultura visual da sociedade. Desse modo, o acesso à informação digital pode ser realizado através de imagens, vídeos, áudios, textos, pela inovação e tecnologia e suas combinações. O autor ainda afirma que, devido à popularidade e à facilidade de uso, essa ferramenta também está sendo utilizada pelo público de instituições culturais.

Budge e Burness (2018) desenvolveram um estudo sobre como o público se relaciona com os objetos do museu através do Instagram. Eles destacaram que, embora esse campo de pesquisa ainda seja pouco explorado, tais estudos desempenham um papel importante no entendimento acerca da interação das pessoas com os museus.

Assim, o presente estudo teve como objetivo analisar as atividades educativas e de DC do Museu da Vida, através do Instagram, nos dois meses iniciais de isolamento social, devido à Covid-19, no Brasil.

\section{PERCURSO METODOLÓGICO}

Segundo Hine (2016), as tecnologias digitais se tornaram parte intrínseca das vidas cotidianas, inseparáveis da existência social, e trouxeram uma série de transformações. Nesse sentido, torna-se necessário pensar métodos de análise que atendam a essa demanda. Assim, configura-se o cenário para a criação de uma metodologia qualitativa com o objetivo de estudar culturas e comunidades, por meio da observação de comunicações mediadas por computador (KOZINETS, 2002).

Encontram-se, na literatura, diferentes nomenclaturas para denominar o estudo de culturas e comunidades na internet: etnografia virtual, netnografia, etnografia digital, webnografia e ciberantropologia. No presente estudo, usaremos o termo netnografia, cunhado na década de 1990 por pesquisadores norte-americanos e popularizado por Robert Kozinets (FRAGOSO; RECUERO; AMARAL, 2011).

A netnografia foi inicialmente desenvolvida em pesquisas na área de marketing, como forma de entender as relações de consumo (KOZINETS, 2014). Volta-se para a observação das comunidades virtuais, on-line ou eletrônicas situadas no ciberespaço (CORRÊA; ROZADOS, 2017). A pesquisa netnográfica trabalha, portanto, com os preceitos da Web 2.0, com olhar direcionado à participação, interação e comunicação do interagente na internet.

Partindo desses pressupostos, realizou-se um levantamento netnográfico dos posts de ações educativas e de DC publicados no Instagram do Museu da Vida. Foram consideradas atividades no período de 16 de março de 2020, dia em que o governador do Rio de Janeiro assinou o Decreto n 46.973 com medidas restritivas para combater a Covid-19, até o dia 16 de maio de 2020, completando dois meses de atividades virtuais. Destaca-se que todos os decretos sancionados tanto pelo governo federal, como pelo governo do estado do Rio de Janeiro, deliberaram o isolamento social a cada quinze dias. Assim, optamos por analisar os dados por quinzena, ou seja, contando duas semanas de atividades.

As atividades virtuais do Instagram do Museu da Vida foram analisadas seguindo três categorias: tipo de apresentação visual, caracterizada pelo tipo de arte expositiva apresentada no post; frequência de atividades por quinzena do isolamento social; e por fim, adesão do público, que se refere à quantidade de curtidas e comentários nas publicações. 


\section{RESULTADOS E DISCUSSÃO}

Após o levantamento netnográfico, foram identificadas 96 publicações durante o período analisado. Em relação à primeira categoria de análise, observaram-se sete tipos de apresentação visual, dos quais cinco são exemplificados na Figura 1. O quantitativo de cada tipo visual está representado no Gráfico 1.

Figura 1 - Tipos de apresentação visual dos materiais postados. 1: Arte gráfica com fotografia e texto; 2: arte ilustrativa; 3: arte gráfica com texto; 4: arte ilustrativa com texto; 5: fotografia e texto.

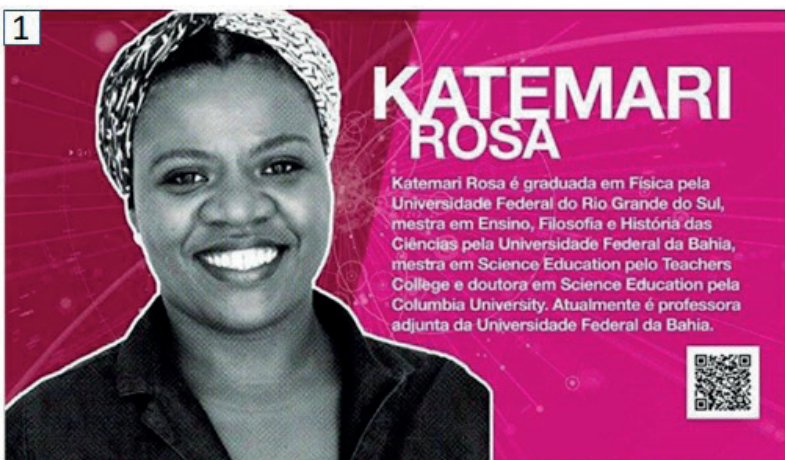

3

Covid-19 / Novo coronavírus

\section{Funcionamento}

do Museu da Vida:

suspensão das

atividades por 15 dias

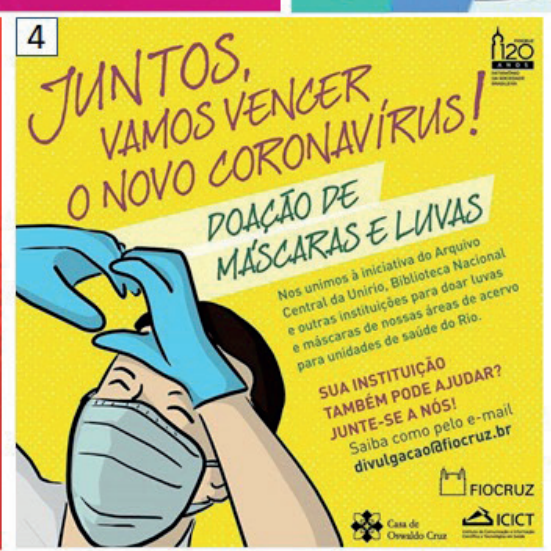

Fonte: Autores, 2020
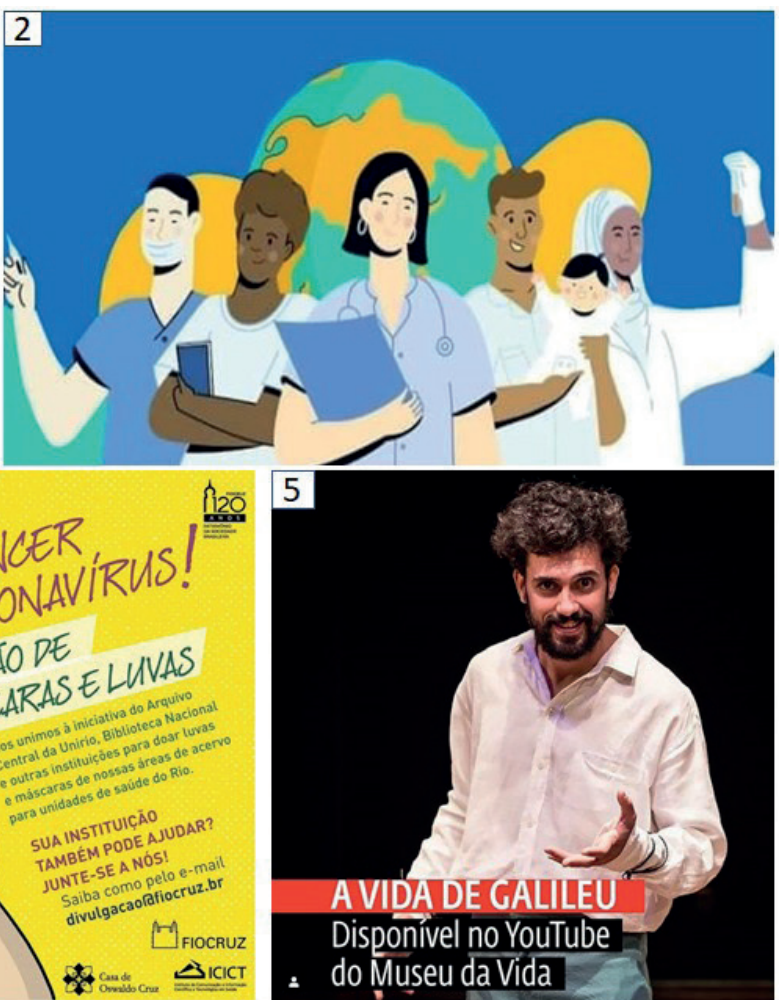

Gráfico 1 - Quantidade por tipo de apresentação visual.

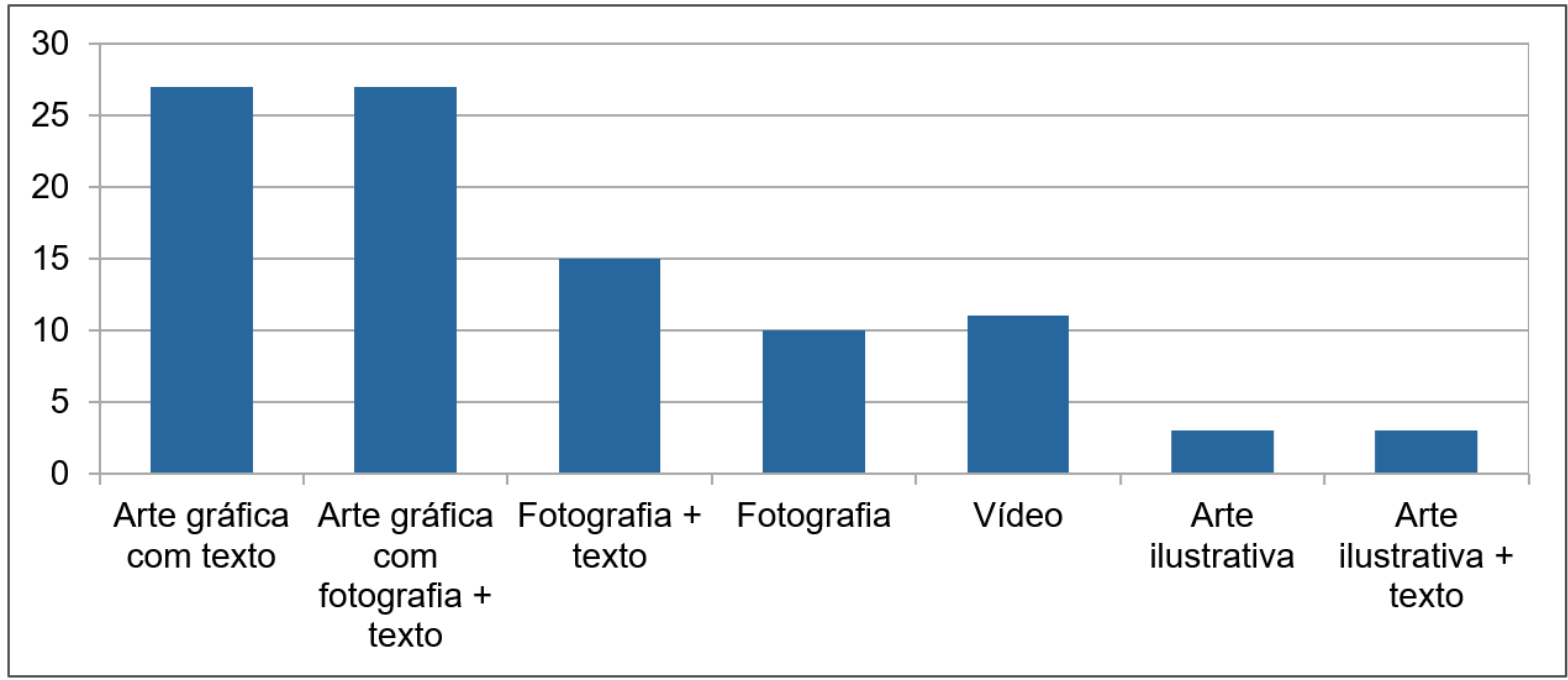


Observa-se que os materiais compostos por arte gráfica com texto e arte gráfica com foto mais texto foram os mais recorrentes. De acordo com Joly (2012), a presença de signos linguísticos, ou seja, textos presentes na imagem ou as acompanhando é fundamental para o processo de significação das mensagens. Assim, podemos inferir que a escolha desses recursos representa um movimento para que o público se aproxime do que está sendo publicado.

No que diz respeito à segunda categoria, foi analisada a frequência de atividades por quinzena, ao longo dos dois meses de isolamento social (Gráfico 2). Percebe-se que há uma crescente com o passar dos dias. Entretanto, na última quinzena, há um aumento expressivo de publicações, sobretudo devido à participação do Museu da Vida na Museum Week.

A Museum Week é uma semana de sete hashtags, com sete temas diferentes, toda dedicada a museus na internet. A princípio, em 2014, quando a Museum Week foi criada na Europa, as iniciativas eram mais voltadas para as redes sociais. Hoje, o evento cresceu, ganhou atenção de vários países e incentiva as instituições a promoverem ações também presenciais. Ressalta-se que a Museum Week foi responsável por cerca de vinte publicações no perfil do Museu da Vida, todas postadas nas duas primeiras semanas de maio.

Gráfico 2 - Quantidade de publicações por quinzena de isolamento social.

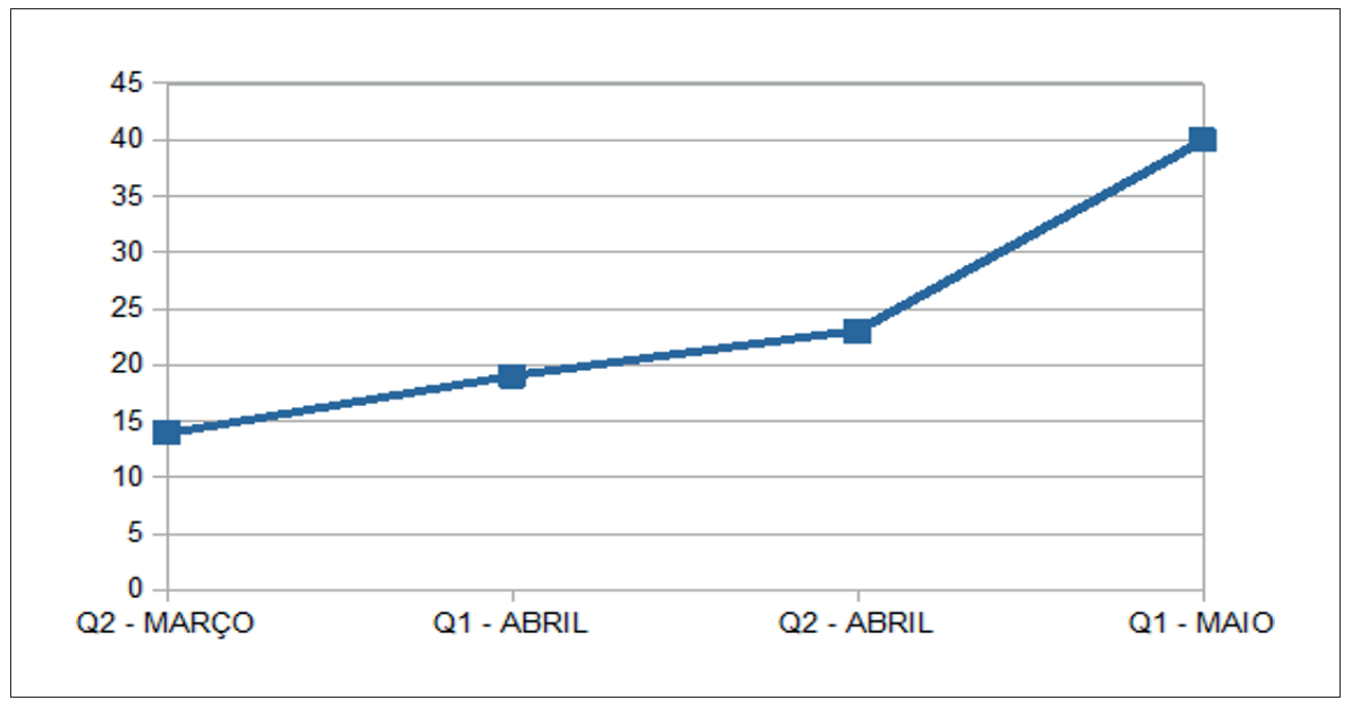

Fonte: Autores, 2020.

Com a análise dos dados, é possível observar uma mudança no perfil visual das postagens do Museu a partir da pandemia. Antes, o Museu da Vida fazia uso, principalmente, de fotos e vídeos, representando o cotidiano de suas atividades. Essa mudança estratégica, possivelmente, relaciona-se à necessidade de fechamento da instituição e à consequente inviabilidade de se continuar representando o cotidiano por meio de imagens e vídeos. Aliado a isso, a incerteza sobre o tempo de fechamento era maior no início do isolamento social, o que, possivelmente não ofereceu clareza para a definição de uma nova estratégia de imediato.

À medida que o "novo normal” foi sendo delineado, conseguiu-se avançar na concretização de novas estratégias, ampliando o uso de artes gráficas, de lives e de postagens. Segundo Gabriel (2010), a análise do ambiente é um dos fatores mais importantes do planejamento e permite a definição de uma melhor estratégia. Por isso, fatores como o ambiente interno da instituição, o público e aspectos externos, como por exemplo, cultural e econômico, devem ser observados constantemente.

A adesão do público às postagens no Instagram foi analisada na terceira categoria. Ressalta-se que, para facilitar a contagem de curtidas em cada publicação, foram criadas interseções. O Gráfico 3 mostra a quantidade de publicações dentro de cada interseção de curtidas. Importante destacar que os números de curtidas, visualiza- 
ções e comentários podem se alterar ao longo do tempo, visto que tais publicações ficam disponíveis a qualquer hora e para qualquer pessoa que faça uso da rede social.

Gráfico 3 - Quantidade de posts por número de curtidas.

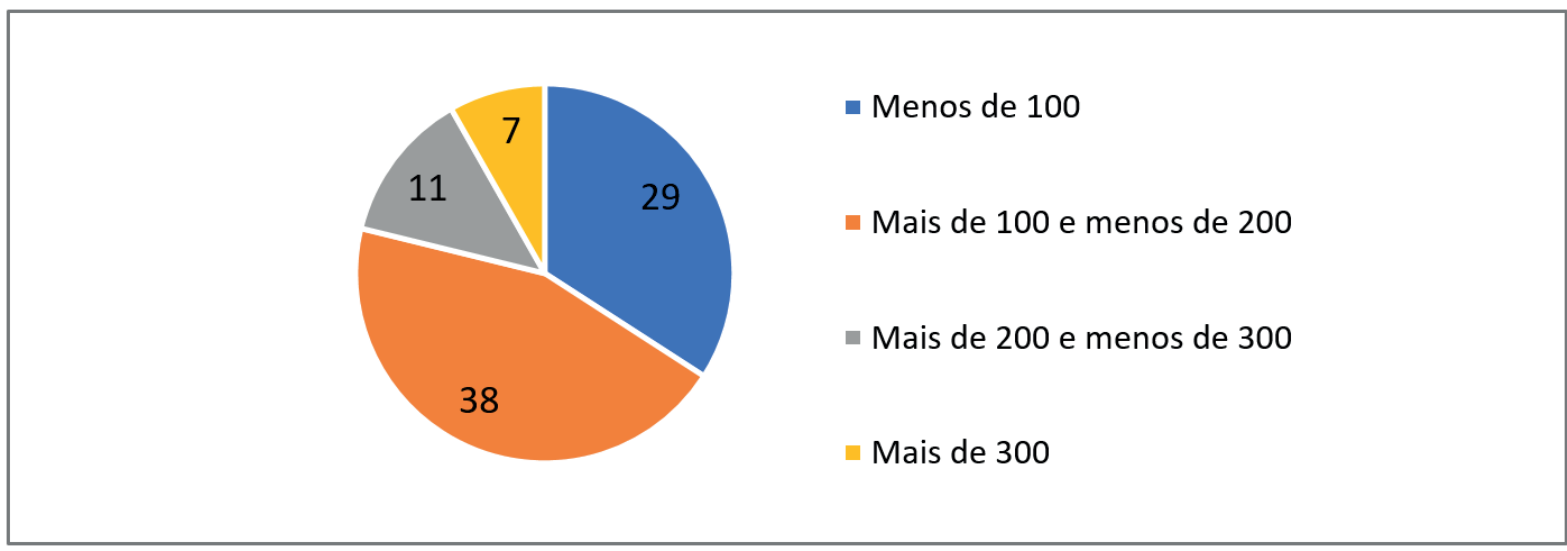

Fonte: Autores, 2020

Curtidas e comentários são indicadores importantes da popularidade de uma postagem, mas nem sempre o post mais curtido é o mais comentado e vice-versa. Para Recuero (2014), o ato de curtir pode representar: uma participação na conversa sem elaboração de resposta; uma sinalização de que a mensagem foi recebida; uma forma de o internauta mostrar para a rede que ele está ali; ou, ainda, um agradecimento pela publicação de informação considerada relevante. Já a ação de comentar traduz uma participação mais efetiva, com real contribuição para a conversação, já que ocorre pela manifestação de resposta escrita, que acontece quando o seguidor tem algo a dizer sobre o assunto.

Das 96 postagens compiladas, sete receberam mais de 300 curtidas. A Tabela 1 apresenta as referidas postagens classificadas das mais para as menos curtidas.

Tabela 1 - Quantidade de curtidas e comentários dos sete posts mais curtidos.

\begin{tabular}{cccc}
\hline Data & Temática & Curtidas & Comentários \\
\hline 17.03 & Alerta de fake news sobre coronavírus atribuída à FIOCRUZ & $\mathbf{8 2 9}$ & $\mathbf{1 9}$ \\
\hline 27.04 & Cientistas Negras: Joana D’Arc Félix de Souza & $\mathbf{4 5 6}$ & $\mathbf{3 1}$ \\
\hline 11.05 & Museum Week - dia 1 & $\mathbf{4 2 2}$ & 5 \\
\hline 25.03 & Doação EPIs para profissionais de saúde do Centro de Saúde & 406 & 11 \\
\hline 20.03 & Alecalizado em Manguinhos & 376 & $\mathbf{2 5}$ \\
\hline 30.04 & Resultado do edital Pró-Cultural 2020 news sobre coronavírus atribuída à FIOCRUZ & 339 & 5 \\
\hline 11.04 & Dica de leitura: artigo sobre divulgação científica e coronavírus & 317 & 6 \\
\hline
\end{tabular}

Fonte: Autores, 2020.

Observa-se que o post do dia 17 de março chama a atenção por ter alcançado um número expressivo de curtidas. Ele traz um esclarecimento sobre uma fake news atribuída à FIOCRUZ, que circulava pelo Whatsapp, com informações sobre o novo vírus. Além de desmentir os fatos inverídicos, a postagem indicava sites da FIOCRUZ e do Ministério da Saúde (MS) como fontes confiáveis para obtenção de informações sobre o tema. 
Ao contextualizar temporalmente essa postagem, percebemos que, na data em que foi realizada, a imprensa noticiava aquela que seria, naquele momento, a primeira morte por coronavírus no Brasil, ocorrida na cidade de São Paulo, onde supostamente foi registrado o primeiro caso importado de Covid-19 no Brasil, em 26 de fevereiro. Os governos estaduais do Rio de Janeiro e São Paulo iniciavam a quarentena. Os brasileiros tinham muitas dúvidas sobre a nova doença. O MS dava início à veiculação de informações sobre regras básicas de higiene, e muitas notícias falsas já circulavam, provocando desinformação.

A atualidade do fato e o apelo do momento parecem ter chamado atenção dos seguidores. Tanto que, no dia 20 de março, outro post sobre fake news também alcançou popularidade. Esse post, além de esclarecer os fatos, convidava os seguidores a interagir com o Museu da Vida e a compartilhar/marcar amigos, no sentido de disseminar fatos verídicos. Além de constarem entre os mais curtidos, os posts sobre fake news relacionadas ao coronavírus estão entre os que contam com maiores números de comentários.

Shu et al. (2017) afirmam que as fake news trazem impactos negativos para toda a sociedade, ainda mais quando se trata de questões de saúde pública. A veiculação de informações falsas, além de levar à desinformação da população, contribui para a propagação de distorções que podem perdurar por muito tempo (LACERDA; RAIMBO, 2019).

A segunda postagem mais curtida, do dia 27 de abril, faz parte do Calendário de Divulgação Científica 2020, ilustrado somente com cientistas brasileiras negras e lançado pela FIOCRUZ neste ano. No dia 20 de março, seria realizada uma contação de histórias sobre mulheres negras, devido à ação dos 21 dias de ativismo contra o racismo. Porém, com a suspensão das atividades, o Museu da Vida optou por homenagear intelectuais negras pelo Instagram. Joseli Maria dos Santos, pesquisadora responsável pela elaboração desse calendário, alega que o intuito principal é contribuir para a promoção da equidade de gênero e raça, além da desconstrução de preconceitos e da discriminação historicamente forjadas desde a época da colonização. Esse segundo post mais curtido trouxe informações sobre a química brasileira Joana D’Árc Félix de Souza. A arte gráfica que ilustra o post traz uma foto da cientista.

De origem humilde, Joana cursou graduação, mestrado e doutorado em Química na Universidade Estadual de Campinas (Unicamp). Atualmente, é professora em uma escola pública trabalhando com jovens em vulnerabilidade social. Atraiu a atenção da imprensa por conta da sua história de superação, quando, em 2019, envolveu-se em uma polêmica sobre um falso diploma de pós-doutorado da Universidade de Harvard.

Em jornalismo, há um conjunto de critérios de relevância que definem se um evento tem ou não potencial para se transformar em notícia. Segundo Wolf (2005, p. 215), eventos que constituem ou representam infrações, desvios, rupturas no curso normal das coisas e que alteram a rotina e as aparências normais são noticiáveis. Tanto a história de superação de Joana, quanto a suposta falsificação do diploma, enquadram-se nesse critério de noticiabilidade.

O terceiro post mais curtido, de 11 de maio, marca o início da Museum Week. A fotografia de capa que compõe o post traz uma imagem difundida nas redes sociais, com profissionais de saúde segurando cartazes pedindo para as pessoas permanecerem em casa. A identificação/empatia com os trabalhadores da linha de frente contra a Covid-19 talvez explique a prevalência deste post dentre os mais populares. Dos 18 posts alusivos a Museum Week, realizados durante a semana do evento e dentro do período de análise, 13 traziam fotografias em que pessoas eram pontos focais.

Destacamos, em nossa análise, que os vídeos não entraram na quantificação do Gráfico 3, pois publicações em vídeo disponibilizam também o número de visualizações, o que representa de forma mais clara o engajamento do público com o post. Esses dados aparecem no Gráfico 4. 


\section{Gráfico 4 - Visualizações por vídeo postado.}

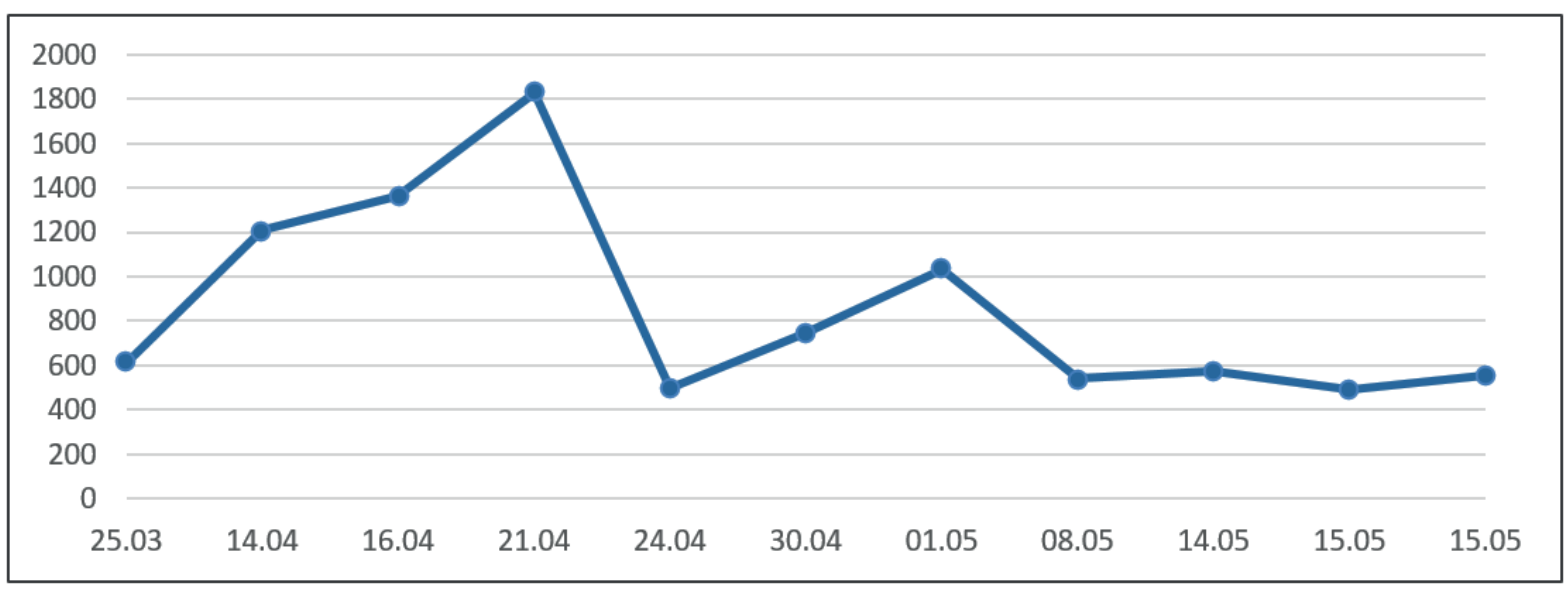

Fonte: Autores, 2020.

Os vídeos mais visualizados, com mais de 1000 visualizações, foram dos dias 14, 16 e 21 de abril e $1^{\circ}$ de maio. O vídeo de 14 de abril refere-se ao espetáculo do Museu da Vida, "Paracelso, O Fenomenal”. O ator mostra um dos experimentos presentes no espetáculo, mas que, devido ao isolamento social, é adaptado para ser realizado em casa. O experimento, chamado de "Caneca Assustadora”, mostra como a gravidade pode atuar fazendo uma caneca pendurada não cair no chão com o auxílio de um lápis, uma chave e um barbante. Essa atividade é voltada para as crianças e possui o objetivo de estimular, divertir e desenvolver uma linha de pensamento sobre o conteúdo abordado no experimento. Entretanto, apesar de interativo, o vídeo não é inclusivo por não possuir legenda ou linguagem em libras.

O vídeo de 16 de abril representa o primeiro da seção "Um Biólogo Responde”. No dia 2 do mesmo mês, o Museu da Vida havia solicitado aos seguidores perguntas sobre a pandemia para serem discutidas por especialistas. Assim, o biólogo Miguel de Oliveira, do Serviço de Educação do Museu da Vida, produziu dois vídeos, postados em 16 e 30 de abril, abordando questionamentos, cujas respostas, eram pouco conhecidas. Ambos os conteúdos dos vídeos possuem formato escrito no site do Museu da Vida, facilitando o acesso de pessoas com deficiência. Considera-se muito importante essa iniciativa de designar um profissional para esclarecer dúvidas sobre a pandemia, ainda mais em tempos de fake news, que estavam em alta nas primeiras semanas da Covid-19 no Brasil.

O vídeo de 21 de abril, o maior em número de visualizações e comentários, também foi produzido por uma atriz do "Paracelso, O Fenomenal". O vídeo aborda o processo de realização do experimento chamado de "Papel que Não Rasga". Nele é apresentado o mistério de um papel que não rasga mesmo exercendo-se força sobre ele. O conteúdo é bastante interativo, mas chamamos a atenção para o fato de não ser inclusivo, fato que acontece com o vídeo de 16 de abril também.

Possivelmente, os vídeos que envolvem experimentos tenham sido vistos mais de uma vez para realização correta em casa. Além disso, as atividades educativas envolveram crianças, que em época de isolamento, necessitam de atividades práticas que sirvam como entretenimento. Esses fatores podem explicar o número elevado de visualizações. Teixeira et al. (2020) afirmam que atividades como essas, em geral, são contextualizadas e interdisciplinares, tornando-se, assim, mais atrativas para o público. E, ainda, despertam o interesse por permitirem que as crianças interajam e manipulem objetos em situações investigativas capazes de gerar reflexão e argumentação crítica (DE LUCA et al., 2019).

O vídeo do dia $1^{\circ}$ de maio, publicado em homenagem ao aniversário de 21 anos do Museu da Vida e aos 120 anos da FIOCRUZ, foi o primeiro de uma série comemorativa que tratou sobre as duas décadas de atividades do Museu. Esse vídeo traz um conteúdo interativo através da gravação de crianças que visitam a instituição e 
são abordadas pela mediadora, que diz: “Vocês sabem onde a gente está?”. O vídeo, além de mostrar as reações das crianças conhecendo a exposição e realizando as atividades junto aos mediadores, também conta com um sociólogo abordando o contexto histórico do Museu.

Por se tratar do primeiro vídeo da série de comemoração e, por trazer de forma dinâmica, curta e informativa o que é o Museu da Vida, poderíamos justificar a expressiva quantidade de visualizações do vídeo. Além disso, o vídeo é acessível, trazendo as palavras de forma bem articulada, com som adequado e legenda em português. De acordo com Conforto e Santarosa (2002), a acessibilidade deve ser vista como uma maneira de disponibilizar a cada visitante interfaces que atendam suas necessidades. Cada vez mais a acessibilidade digital assume papel fundamental, visto que, com o surgimento de novas tecnologias, o processo de informação torna-se mais interativo.

\section{CONSIDERAÇÕES FINAIS}

Após a análise dos dados, foi possível perceber o reflexo da atuação de museus de ciências na sociedade, por meio de atividades que promoveram educação, informação, lazer e cultura. O Museu da Vida conseguiu realizar atividades de DC e educativas, mesmo após seu fechamento. Para tal, utilizou-se de recursos textuais, imagéticos e audiovisuais promovendo a integração entre o Instagram e outras redes sociais e, ainda, com o site institucional.

Uma vez que o recorte temporal foi referente aos dois meses iniciais do isolamento social e, considerando que o Museu da Vida é parte integrante da estrutura de uma das maiores instituições científicas do Brasil na área de saúde, era de se esperar que houvesse expressivas postagens de elementos (textuais, gráficos e audiovisuais) que remetessem à pandemia, vírus, coronavírus, Covid-19, vacina, entre outros.

Apesar da manutenção de atividades de DC e educativas, é importante considerar que, em museus, o aspecto da interatividade é fundamental, assim como o aspecto sensorial é importante e fica limitado diante do uso de tecnologias digitais. Por outro lado, há aspectos positivos a se destacar, como a oportunidade de ampliar o alcance das atividades para áreas externas ao espaço físico do museu. O uso do Instagram pode contribuir para despertar o interesse e gerar curiosidade para que futuras visitas aconteçam presencialmente. Portanto, o Instagram, como instrumento de DC, não se sobrepõe, mas complementa as atividades presenciais e ganhou maior relevância em tempos de pandemia.

Muito além de uma mera adaptação de atividades em um momento crítico, os achados obtidos a partir deste estudo apontam para uma nova forma de comunicação e relacionamento entre o Museu e os seus públicos, característica da sociedade do conhecimento, e que tende a perdurar mesmo após a pandemia.

\section{Agradecimentos}

À Coordenação de Aperfeiçoamento de Pessoal de Nível Superior (CAPES) e ao Conselho Nacional de Desenvolvimento Científico e Tecnológico (CNPq) pelo apoio à pesquisa. 


\section{REFERÊNCIAS}

BOYS, J.; BODDINGTON, A. Museums and higher education working together: Challenges and opportunities. Farnham: Ashgate, 2014.

BUDGE, K; BURNESS, A. Museum objects and Instagram: agency and communication in digital engagement. Continuum, v.32, n.2, p.137-150, 2018.

CAMPOS, G.E; COSTA, H. Caracterização dos perfis comerciais na rede social Instagram. V Brazilian Workshop on Social Network Analysis and Mining, Anais... SBC, p.55-66, 2019.

CONFORTO, D.; SANTAROSA, L. Acessibilidade à web: internet para todos. Informática na educação: teoria \& prática, $v .5$, no. 2 (2002).

CORRÊA, M.V.; ROZADOS, H.B.F. A netnografia como método de pesquisa em ciência da informação. Encontros Bibli, Santa Catarina, v. 22, n.49, p. 1-18, maio/ago., 2017. Disponível em: https://periodicos.ufsc. br/index.php/eb/article/view/1518-2924.2017v22n49p1. Acesso em: 08 maio 2020.

COUNTS, C. We Are Truly Getting Through This Together. Informal Learning Review. A Publication of Informal Learning Experiences. ILR Special Issue, 2020.

DECATUR, R. Reimagining. Informal Learning Review. A Publication of Informal Learning Experiences. ILR Special Issue, 2020.

DE LUCA, A. G; SANTOS, S. A; DEL PINO, J. C; PIZZATO, M. C. Na experimentação contextualizada e interdisciplinar: o papel dos questionamentos, da argumentação e da leitura. Scientia Naturalis, v.1, n.2, p.267280, 2019.

DRUMM, M. Hands-On, Hands-Off, or Something New. Informal Learning Review. A Publication of Informal Learning Experiences. ILR Special Issue, 2020.

FRAGOSO, S., RECUERO, R., AMARAL, A. Abordagens etnográficas. Métodos de pesquisa para internet. Porto Alegre: Sulina, 2011. P.240

GABRIEL, M. Marketing na Era Digital: conceitos, plataformas e estratégias. São Paulo: Novatec Editora, 2010.

HINE, C. Estratégias para etnografia da internet em estudos de mídia. In: CAMPANELLA, B., BARROS, C. (org.) Etnografia e consumo midiático: novas tendências e desafios metodológicos. 1.ed. Rio de Janeiro: E-papers, 2016.

HU, Y; MANIKONDA, L; KAMBHAMPATI, S. What we instagram: a first analysis of instagram photo content and user types. Eighth International AAAI conference on weblogs and social media, 2014. Disponível em: https://www.aaai.org/ocs/index.php/ICWSM/ICWSM14/paper/ view/8118/8087. Acesso em: 5 jun. 2020.

JOLY, M. Introdução à análise da imagem.14 ed. Campinas: Papirus, 2012.

KOZINETS, R. V. The Field Behind the Screen: Using Netnography For Marketing Research in Online Communities, 2002. Disponível em: https:/libraryh3lp.com/file/96kn8zcetdjxyt@web.libraryh3lp. com/1590100962640.pdf?t=6JiC63FRXXUJqTfZ9Ce8Me. Acesso em: 21 maio 2020.

KOZINETS, R. V. Netnografia: realizando pesquisa etnográfica online. Tradução: Daniel Bueno. Porto Alegre: Penso, 2014. VitalBook file. 
LACERDA, G. H; RAIMBO, L. C. F. D. D. O jornalismo na era digital e as fake news. Cad. Letras UFF, v. 30, n. 59, p. 133-146, 2019.

MASSARANI, L.; CASTELFRANCHI, Y.; FAGUNDES, V.; MOREIRA, I.; MENDES, I. O que os jovens brasileiros pensam da ciência e da tecnologia? 2019. Disponível em: http://www.coc.fiocruz.br/images/PDF/ Resumo\%20executivo\%20survey\%20jovens_FINAL.pdf. Acesso em: 29 abr. 2020.

PSCHEIDT, C; LORENZETTI, L. Contribuições de um curso de formação continuada para a promoção da alfabetização científica de docentes no Museu da Terra e da Vida. Alexandria, v.13, n.1, p.155-180, 2020.

RECUERO, R. Curtir, compartilhar, comentar: trabalho de face, conversação e redes sociais no Facebook. Verso e Reverso, v. 28, n. 68, p. 114-124, maio/ago., 2014.

SHELDON, P; BRYANT, K. Instagram: Motives for its use and relationship to narcissism and contextual age. Computers in human Behavior, v.58, p.89-97, 2016.

SHU, K; SLIVA, A; WANG, S; TANG, J; LIU, H. Fake news detection on social media: a data mining perspective. ACM SIGKDD Explorations Newsletter, v.19, n.1, p.22-36, 2017.

SUESS, A. E. C. Art gallery visitors and Instagram. Masters diss., University of Arts, London, 2014. Disponível em: https://www.academia.edu/12086365/Art_Gallery_Visitors_and_Instagram. Acesso em: 30 de maio de 2020.

TEIXEIRA, A. C. P; MENDES, L. S; GODINHO, M. A. S; MÓL, A. P. A importância das aulas práticas no ensino-aprendizagem em ciências: um relato de experiência de bolsista do PIBID. Revista Educação, Meio Ambiente e Saúde, v.1, n.2, p.148-157, 2020.

WOLF, M. Teorias das Comunicações de Massa. São Paulo, Martins Fontes, 2005. 295p. 